\title{
The Precise Poverty Targeting Mechanism Construction in Ethnic Areas
}

\author{
Chen Zhongwei \\ School of Economics, Sichuan University, Research Center of Sichuan University, Chengdu; 610064, China
}

Keywords: Ethnic areas; precise poverty; poverty alleviation; targeting mechanism; path construction

\begin{abstract}
Poverty in ethnic areas is characterized by historic, complex, fragile and sensitive characteristics. From the poverty alleviation goals precision of ethnic area is the core, the precise poverty poverty target batch classification is the foundation of national and regional poverty alleviation accurate precise poverty targeting mechanism needs three aspects of minority area poverty alleviation precise targeting mechanism construction causes the target. Put forward to improve the national minority area poverty line, the poor recognition is introduced in the design of land index, introduction of gender sensitive indicators in poor definition and segmentation standard and establish the poor recognition mechanism allows the poor people to participate in four major countermeasures to promote ethnic construction precision aiming mechanism of poverty alleviation.
\end{abstract}

\section{Introduction}

In 2012, in the investigation of Fuping County of Hebei Province, general secretary Xi Jinping pointed out: "we must make efforts to support poverty alleviation and development work, the difficulties of the masses out of poverty, as they solve problems, so that the fruits of development to benefit all the people, this is our party always adhere to the important embodiment of serving the fundamental purpose of serving the people, is one of us the party and government responsibility. In 2013, when investigating Xiangxi Tujia and Miao Autonomous Prefecture in Hunan Province, general secretary Xi Jinping put forward specific requirements for the concept of "precision poverty alleviation" for the first time. He said: "poverty must be realistic, according to local conditions, in the process of precise poverty alleviation, avoid shouting slogans, it is not some high goals." In November 2015, in the central poverty alleviation and development conference, general secretary Xi Jinping pointed out clearly: "efforts to eliminate poverty, actively improve people's livelihood, and gradually realize common prosperity, is the essential requirement of socialism."." The precise poverty alleviation, emphases and difficulties are all in the minority areas. The reason is that the vast minority areas of poor traffic, facilities to be perfect, personnel living is not concentrated, it is difficult to achieve its goal of accurate poverty alleviation. Implement precise poverty in some minority areas, we must implement the refinement of poverty reduction strategies. Based on the mechanism of poverty alleviation, the adjustment of poverty alleviation mode was changed, the traditional effect of relying solely on economic growth was changed, and more attention was paid to the targeted, and the direct intervention of poverty alleviation was carried out on target groups. Therefore, based on the current social conditions, the implementation of precise poverty alleviation in the vast minority areas, that is to say, to help all people gradually find out a suitable, distinctive way to get rid of poverty.

\section{The multidimensional characteristics of poverty in Ethnic Areas}

\subsection{Historicity}

In the majority of ethnic minority areas, poverty is a long plagued local problems. Generally 
speaking, people habitually refer to the old revolutionary base areas, minority areas, border areas and poor areas as "old, small, border and poor" areas. The geographical location and natural environment, the majority of ethnic minority areas in the border areas, and most were located in the plateau, desert and arid area, the climate is relatively poor, prone to natural disasters, most areas are not suitable for human habitation. The historical point of view, in the class society, the minority areas of extremely serious exploitation and oppression and inequality, these areas people's freedom later than in other areas. So, the problem of poverty is not the majority of ethnic minority areas recently formed, nor set up after the new Chinese formation, poverty in minority areas has historic, deeply ingrained, and intergenerational inheritance. Ragnar Knox famous professor at the Columbia University has proposed that the existing problems in the developing countries vicious spiral of poverty, in the majority of ethnic minority areas, there are vicious spiral of poverty. After the new Chinese was founded, China quickly established the basic principles of national work, the provisions of common prosperity in ethnic minority areas, ethnic unity and equality among ethnic minority areas, for the majority of the party and the country vigorously implement poverty alleviation work, the majority of the minority areas of economic and social development has made great progress, eased the problem of poverty. But today, some of the ethnic minority areas is still the economic development of the short board, in the "13th Five-Year" development period, as the completion of a comprehensive well-off society in the decisive stage, precise poverty alleviation in minority areas is the key and difficult.

\subsection{Complexity}

In many ethnic minority areas, by the natural environment, ecological conditions are generally fragile, natural productivity level is low, single production mode of agriculture and animal husbandry, and most of them with extensive mode of operation, the majority of farmers and herdsmen is generally dependent on the weather, and the formation of ecological poverty. As for institutional poverty, Myrdal, a representative of the new institutional school, has pointed out that institutional factors are one of the important factors that cause poverty in a region. "Institutional poverty mainly refers to the normal learning and work performance, but due to reasons of acquired lack of education, lack of policy identity restriction and old customs and other aspects of the defects of the system of poverty, and the poverty has obvious intergenerational transfer characteristics, but through the system design and public policy, can be eliminated." At present, the supply of basic public service system in China has yet to achieve national unity, socialization, equal service is not standard, in some ethnic minority areas, basic public services than other areas of level, poor quality, less quantity, low level, basic education and basic medical and health care social security coverage is not advanced. The scope of small farmers and herdsmen lack of development opportunities, development ability is restricted to a great extent, can not rely on their own efforts to improve survival and living conditions, out of poverty is affected. Economic poverty mainly refers to the relatively low income level of poor farmers and herdsmen, and even can not maintain the basic survival type needs, but the development needs are more difficult. The social poverty mainly for basic social development of minority regions is relatively weak, a serious shortage of education, health care, social security and infrastructure related to the provision of public services, in many poor areas, lack of teachers, health care facilities and the investment is less. Special care, relief and pension insurance system is not perfect, these factors seriously restrict the development and progress of the society in minority areas. The culture of poverty mainly refers to poor farmers and herdsmen have low levels of education, idea is relatively backward, lack of knowledge and skills, labor productivity is low, the lack of innovation and entrepreneurship awareness, which led to the economic development of this region is restricted by its own level, at the same time, a lot of farmers and herdsmen to stick to the traditional concept of poverty alleviation, wait for support, not to set up a new type of poverty the concept of poverty, lack of initiative consciousness.

\subsection{Vulnerability}

The concept of frailty was originally derived from the field of ecology, which is mainly used to describe the ability of the region to resist external interference and its stability. In the face of shocks, 
the main poverty in poor areas may be the ability to deal with the impact of risk. Because of various reasons, in our country the majority of ethnic minority areas, generally have many risks, risk resisting ability is very limited, so, compared with other areas, the poverty in minority areas is cannot withstand a single blow. First of all, in the vast minority areas, the objective ecological environment is relatively fragile, and the frequency of natural risk and disease risk is higher. At the same time, in the majority of ethnic minority areas, basic public services related to the existence of serious deficiencies, many poor people, they generally lack the viability of effective, not based on their own conditions for economic development, can effectively explore the local economic development channels, a serious shortage of capacity to help themselves. In addition, through the research and analysis of the poverty reduction in the past practice and found that most of the ethnic minority areas is used as the basis, or simply transfer payment as the main "blood transfusion" type poverty alleviation, the "blood transfusion" poverty itself has many limitations, only suitable for short-term relief, can not play the role of long-term mechanism the. At the same time, these areas to complete the short-term tasks, most of them gradually evolved into "fattening" mode of poverty alleviation, the so-called "spoil things by excessive enthusiasm", this extensive poverty alleviation mode, not only can not fundamentally solve the problem of poverty, easily lead to the people in poverty, and the population in poverty, poverty renewed will be more serious.

\subsection{Sensitivity}

Throughout history, ethnic issues have always been very sensitive issues, therefore, many ethnic areas are also very sensitive areas. China is a typical multi-ethnic country, each ethnic group is equal to each other, and they fuse with each other in the land of china. The ethnic equality, ethnic unity and common prosperity of all ethnic groups is our party and country in the minority areas of the basic principles of the nation must be adhering to the "mutual understanding, mutual respect, tolerance and appreciation, mutual learning, like pomegranate seeds, cling together". However, due to the combined effects of various factors, at present, China is in the primary stage of socialism, in terms of the level of economic development, social stability, cultural prosperity, differences between different ethnic groups has always existed, the development level of the minority areas is far behind other regions. If this situation can not be timely alleviated, or even allowed to continue to deteriorate, easily lead to the majority of ethnic groups have strong dissatisfaction with society and the state, is not conducive to the country's long-term stability.

\section{Minority area poverty alleviation precise targeting mechanism construction causes}

According to the precision of poverty alleviation in minority areas, is to focus on different environment and different in poor areas, poor farmers, actively use scientific and effective procedures for the implementation of the poverty reduction target the poor governance, including accurate identification, precise and accurate management assistance. Only accurate identification of the poor population, explore the right path to poverty alleviation, and persevere in promoting poverty alleviation work, we can receive the ideal effect of precision poverty alleviation.

\subsection{The precise target poverty alleviation precise poverty alleviation in minority areas is the core}

In the majority of ethnic minority areas in China, poverty alleviation is carried out actively, with the emphasis on doing solid work, doing practical things and giving actual results. At present, in China's minority areas, the poverty alleviation work, both in the identification of poor people, and the formulation and implementation of the poverty alleviation policy, lack of fine work. Since the middle of 80s of last century, the poverty alleviation units of our government mainly rely on the poverty-stricken areas at the county level. In 2001, China's special poverty alleviation 150 thousand village level poverty area. In 2011, the government designated 14 contiguous poor areas, the classification of key poverty alleviation. The rural poverty alleviation work, its main characteristic is the area delineated, not yet identified to households. In the short term, this kind of poverty alleviation 
mode fully focuses on policy and capital resources, which can effectively help some poor people to get rid of poverty, or create rigid infrastructure for some poor groups to get rid of poverty. However, when the flood irrigation type of poverty alleviation work, resulting in the majority of China's ethnic minority areas and poverty-stricken areas, there are two types of group worthy of attention: one is not always true poverty groups, or does not meet the homogeneity of poverty alleviation policy is related to their ability, or simply do not have out of poverty and the quality of this group is the focus of the current concern of the precise poverty; the other is once again after returning to the poverty groups, they or illness, or because of poor management and other reasons, resulting in poverty alleviation work not lasting, the final is repeated and low efficiency. In the vast minority areas, the implementation of precision poverty alleviation, covering the precision identification, precision assistance, precision control and accurate verification and other content, the core of its work is precision. We must take the concept of precision as the core concept of the whole poverty alleviation work, and then go through the whole process of poverty alleviation work.

\subsection{Poverty alleviation target batch classification is the basis for precise poverty alleviation in Minority Areas}

The implementation of precise poverty alleviation in the minority areas, must be based on the requirements of the general secretary Xi Jinping, to establish the concept of partial classification of poverty alleviation, relying on support the development of a number of production and employment, relying on a number of relocation and resettlement, relying on a number of policy transparency, relying on medical aid to support a number of. The so-called relying on support the development of a number of production and employment, is to continue to strengthen the business training and cultivation plan, according to local conditions, and establish the related characteristics of supportive policies and mechanisms, so as to help a large number of related hardware and software with the basic conditions of the population, so they quickly out of poverty; relying on the relocation and resettlement of a group, is for the poor because of the bad part where natural conditions and other relevant factors, still do not have the basic conditions of poverty alleviation of poverty, there are plans to relocate them to the relocation, the natural conditions are relatively good place to live, and then continue to implement the relevant supporting measures, until they are completely out of poverty; relying on the policy fallback group, is on the part of labor ability is relatively low, also or has lost the poor ability to work, no longer in employment training, but by low The civil relief way, to guarantee the basic life; relying on supporting a number of medical assistance, assistance is part of the group, gradually ease medical pressure, eliminate poverty, increasing poverty phenomenon, at the same time, to prevent illness, no lead to national minority area poverty alleviation work return phenomenon.

\subsection{Minority area poverty alleviation precise target identify mechanism}

In the majority of ethnic minority areas to implement precision poverty alleviation, we must avoid the emergence of two types of errors: one is to abandon the true type of error, that is, some eligible target groups did not fully benefit. The other is the error of the existence of pseudo type, that is, some people who do not meet the conditions instead enjoy the social policy. At this stage, in some minority areas, while carrying out precise poverty alleviation, we must greatly improve the timeliness of the process design. The implementation of precision poverty alleviation, the primary path is the scientific design of precision poverty alleviation workflow mechanism, including the precise identification of the majority of poor households, precise assistance, precision control and accurate verification, such as four links. Precise identification is the key process of precise poverty, migration should be made to prevent the target, aiming to ensure poverty alleviation assistance must be in accordance with the requirements of the object; the precise cause of poverty and poor households out of poverty, through some specific measures to support the poor; precision control requirements for the poverty alleviation work must be performed in real-time tracking and control, on the basis of poverty alleviation the progress of the timely adjustment; accurate verification is to ensure that an important means of poverty alleviation effect, accurate requirements in the relevant policy, must be timely to assess the effect of poverty alleviation, culminating in the poverty alleviation work, the formation of target 
identification, poor governance, dynamic management, performance verification, success out of poverty, and a series of follow-up work process.

\section{Minority area poverty alleviation precise targeting mechanism construction path}

In our country the implementation in the ethnic minority regions of antipoverty target mechanism design, although the poverty alleviation action pays more attention to the target group, but in the process of defining and distinguishing the poor, or too bureaucratic and cowardice, few poor people participate in the specific identification of the poor, at the same time, in the whole process of project design also, the lack of the most important elements of the poor is the goal of the project, many projects were enacted into rural development scheme of ordinary, which eventually led to the benefit of the project is very difficult to penetrate to the really poor. The geographical and cultural characteristics of the ethnic minority areas in China based on taking anti-poverty target to design effective, must be based on the poor, to reflect the specific content related degree, local poverty poverty, poverty object feature specific needs, similar to this, such as geographical area, population and climate related factors must be to be considered. In view of the scientific and operational needs of the targeting mechanism of poverty targeting, the aim of anti-poverty targeting mechanism in minority areas should be constructed from the following aspects:

\subsection{Improve the national minority area poverty line}

Improving poverty line standards for ethnic minority areas has always been one of the important practices for poverty alleviation in the minority areas of china. As far as the poverty line standards in the minority areas are concerned, there are mainly three in the past twenty years, namely, "26" standard, "58" standard and the annual per capita net income standard of 265 yuan. If you do not consider the three poverty line determination method is reasonable, only from the poverty-stricken areas in minority areas and the vast majority of Chinese area, only "26" and "58" standard of care reflects the national minority area to a certain extent, the standard is difficult to reflect the minority areas of special poverty depth and poverty the strength of this point in recent years, performance is very obvious. If the "26" standard and the "58" standard also consider the economic development of rural market in some minority areas lag factor, at the same time there are objective difficulties, output is converted into the monetary income that, in recent years, in the minority regions and the Chinese market, to 265 yuan per capita net income as defined in the standard, this single index of absolute poverty will be the development of the original differences are clear. At the same time, the level of poverty line, because most of the climate in minority areas is relatively poor, natural disasters, population is not concentrated in many rural towns and the distance of the center of the market is relatively distant. Based on a variety of reasons, the population in these areas needed for the survival of calorie intake is much higher than in other regions, the average level of spending on food, clothing and living requirements are also higher than the national most rural areas, 265 yuan is difficult to maintain the majority of poor minority population survival requires saturation temperature. So, according to the annual per capita net income of 265 yuan for the standard, and then designated the poverty line the minority areas of our country, while reflecting the national poverty alleviation action integrity and timeliness, but kill the special geographical environment in ethnic minority areas requirements. In view of the minority areas the climate is relatively poor, natural disasters, population concentration and other characteristics, the special needs of the majority of minority poverty population needed in maintaining the survival of the more. Therefore, in the specific operation, the poverty line standards for minority areas should be appropriately improved. As far as the specific needs are concerned, it is necessary to improve the existing poverty line calculation methods. Because the majority of ethnic minority areas of the regional environment and poverty is unique, the reference factors of the poverty line based on the first introduction of some indexes, such as geographical area, population, the average disaster loss rate, and frequency of illness back to education because of poverty rate. In the specific operation process, can be divided into the poverty line, the type of food and non food poverty line of two of the poverty line, said if the poverty line by 
$\mathrm{X}, \mathrm{Xl}$ said the food poverty line, $\mathrm{X} 2$ said the non food poverty line, then: $\mathrm{X}=\mathrm{Xl}+\mathrm{X} 2$; similarly, the foundation for ethnic minority areas relative poverty, the per capita expenditure of education and medical treatment, such as pre disaster loss estimates, can also put the calculation method of the poverty line and then simplified to: $\mathrm{X}=$ current standard of absolute poverty line + cultural education expenditure + natural disaster loss + medical care expenditure.

\subsection{The introduction of land index in the poor recognition design}

In the actual operation process, whether a person with poor standard is also very important to determine the standard to measure whether a person is poor, has its own meaning in terms of absolute poverty, it mainly refers to a person or a family can not reach the lowest standard of the society, the lack of relevant information and services to maintain survival. However, the subsistence materials and services needed for subsistence can be realized not only by currency trading, but also by material support. Is the per capita net income of 265 yuan of the index, it is a typical economic index, although to a certain extent reflects the requirements of the market economy, but for some poor minority areas, the development of the market economy is relatively slow, the monetary income of the relevant economic indicators can not fully measure or represent the status of the majority of assets family owned. In some minority areas where market transactions are not popular enough, especially in some remote pastoral areas, the wealth of the vast rural families remains in the land, cattle and sheep, food and housing and other material levels. So, to replace the whole concept of income and property by the per capita net income, itself is a great misunderstanding in the minority areas of wealth, repeatedly stressed that the economic index per capita net income, easily lead to those rich materials and the lack of monetary income families to be incorporated into the government anti poverty and development of the project. The resource allocation level, the amount of resources will eventually cut to real poverty, which led to the "strong not weak" problem in the system. Therefore, in the minority society, pure is similar to the per capita net income poverty index system can not effectively distinguish between the poor, the poor minority areas, abandoned the wealth index form of matter, it is not realistic. So, for a single economic index of past dependent change in the poor definition and distinction in the process of introducing some known poverty standard, rather than academic terms, for the majority of ethnic minority areas of anti poverty targeting mechanism, is undoubtedly of great breakthrough value. Due to the vast number of minority poverty population on the concept of money is relatively fuzzy, their labor output is difficult to translate into monetary income, non-agricultural industries in these areas are not developed, many poor people mainly rely on the land and related data of land they owned, is a useful indicator of its wealth status so, to distinguish, in the existing index system, must increase the land index, to the number of per capita possession of land for supporting the reference standard, must be carried out with the land survey work. Although this standard may increase the workload for the government, anti poverty but from the successful experience of foreign countries, to distinguish the poor work, a modest increase in the workload is very necessary, the poverty reduction effect is far higher than the relevant action goals are not accurate.

\subsection{The introduction of gender sensitive indicators in poor definition and segmentation standard}

Whether gender sensitivity indicators are particularly important in the definition and segmentation of the poor is particularly important. But according to the author shows that general survey of ethnic minority areas, most of the minority areas is still in a male dominated society, while women earn the family income accounted for more than $0.3 \%$, does all the housework and more than $0.7 \%$ of the agricultural labor, however, among them, most people did not have assets in, bear the enormous economic pressure, but also bear the social environment is not just around, whether in terms of health and safety, or in status and self-esteem, in the minority areas, social network system will always be blocked by them. Except for those lonely disabled and other special poverty, women may be the living conditions of the minority areas is relatively miserable population, the majority of women are plagued by poverty and hunger, they are the poorest of the poor. However, there are few projects that can take into account gender equity and women's participation in the relevant poverty alleviation 
actions in minority areas, and only the activities related to the operation of the women's Federation will take into account the whole group of women. At present, in the majority of ethnic minority areas, the statistical work has not yet established a gender sensitive indicators of poverty, poverty related research report of the government also failed to separate on poverty of women, many village poverty reduction plan not involving sex, even in those who emphasize women's participation in rural development programs and Anti-poverty projects, also failed to participate because the degree of women as the index of special, in the course of implementation, and ultimately lead to women being ignored. In short, in the majority of ethnic minority areas, in some anti-poverty policies, with little regard to the factors of gender, the gender perspective and index to monitoring and evaluation will be more difficult, even taking into account these factors, only the gender as a special content for discussion, and no as the main body to the policy objectives and policy measures, these factors led directly to the policy of poverty alleviation and development plan in gender blind. How to listen to the aspirations of women, meet the needs of women, and ensure that women participate in the whole process of development projects, not just as beneficiaries. In recent years, these problems have been repeatedly stressed in the field of development, but in terms of the vast minority areas, the whole poverty alleviation work has not attracted widespread attention. Due to the lack of poverty statistics related to gender, easily lead to discriminatory anti-poverty work difficult to carry out, therefore, in the process of promoting anti-poverty plan, personnel working in the government must continue to strengthen the gender poverty statistics collection and sorting, and gradually will advance to the system construction of the poor definition and subdivision index then, according to the relevant project construction, continuously strengthen the national minority female special anti poverty project. In addition, it is necessary to continuously strengthen the training of the gender consciousness of the government staff in the minority areas. Relying on training to improve the social status of gender sensitive anti poverty project staff gradually promote the project staff gradually learn how to empower women, how to guide the participants rather than passive acceptance of positive thinking. For the implementation of the project is concerned, we must understand and grasp the gender related knowledge, to fully grasp the channel and the trend of its development, on the whole, the minority women concern gradually into the process of project implementation, and to ensure that the women involved in the whole process of project planning.

\subsection{Establish the poor recognition mechanism allows the poor people to participate in}

In ethnic minority areas, the method of differentiating the poor from the per capita net income is not applicable. Because it is difficult to accurately identify poor households, in the implementation process, leading to poverty alleviation project easily into trouble, the poorest of the poor resources, usually will be withheld or transferred. In the vast minority areas, the fuzziness of poor people's identification is widespread, mainly because of the defects in the targeting system of the anti-poverty targets. In view of the current situation, the national minority area targeting mechanism design, especially in the recognition mechanism of the poor, almost all the poor recognition around the government main body to construct the system, the design of this kind of top-down easily lead to poor identification with a strong color of bureaucracy. In minority areas, poverty is mainly judged by the government officials; and the flow of poverty alleviation resources is mainly guided by the identification of government interests. To ensure equal membership, and ensure every member has the rights of self selection. From the advantage point of view, all the farmers with membership should be fully respected and excavated to provide the farmers with their own advantages, and provide them with demand expression mechanism. In this part, to confirm the identity of the farmers themselves do not have the right to speak, and these people just in the community household poverty situation is very clear, poor ratings they obtained also can meet the specific requirements and geographical background. In a certain sense, this aspect is the contempt of the wisdom of the minority poverty population, on the other hand, the poor population should have the power to plunder. In order to amend this defect, we must constantly improve the management system of poverty alleviation, based on the existing feedback design, let the poor people of ethnic minorities actively participate in the whole system of anti-poverty. And specific to the poor identification and anti poverty objectives 
aimed at the design, not only let the poor themselves have the opportunity to participate in the identification of the poor, the poor also have the power to determine and consider their benefit priority. In this regard, the experience of India deserves our follow - up, and its comprehensive rural development poverty alleviation project is relatively mature, through the establishment of an open division system, and repeated verification. Therefore, the majority of China's ethnic minority areas based on poverty, poverty can produce the recipient list through the community meeting to confirm, sorting and publicity, once the opposition accounted for a certain proportion of community residents, division of work must be re poor. Although this method can not solve all the problems existing in the process of poor people identification, it is effective to avoid the possible deviation in the differentiation mechanism for poor people.

\section{References}

[1] Guo Peixia on the establishment of anti poverty targeting mechanism in ethnic minority areas [J] survey World 2007 (11) The multidimensional characteristics of poverty in minority areas

[2] Li Deying precise poverty countermeasures [J] Economic Research Guide 2016 (08)

[3] Yanbing institutional poverty spawned inclusive growth: looking for a new idea of poverty reduction [J] reform of 2014 (9)

[4] Has had a stream, Fusheng. Basic public services on the mechanism of [J] reduction effect poor Guizhou social science 2012 (12)

[5] Xiong Kunxin how to realize the mechanism of poverty alleviation in minority areas and the precision of the $[\mathrm{N}]$ China national newspaper 2017.3.31 